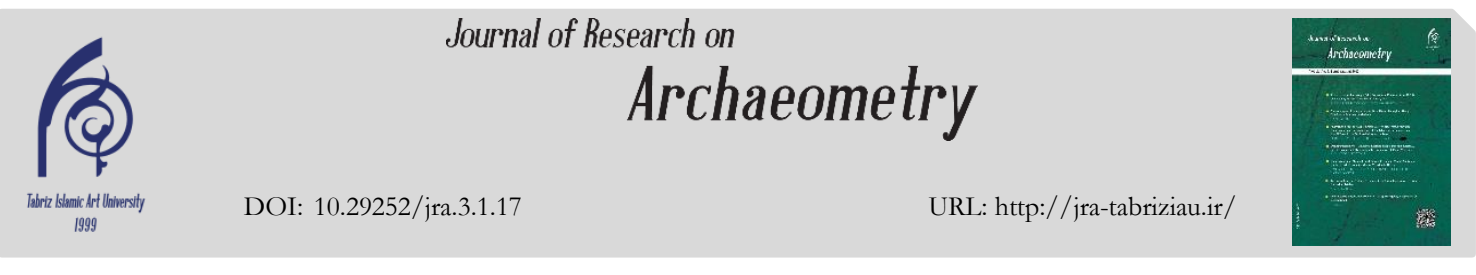

Original Paper

\title{
Identification the Structure of Colorants Used on the Late Bronze Age Ceramics of Eastern Lake Urmia Based on the Specimen from Kul Tepe, Ajabshir
}

\author{
Umm al-Banin Rastineh ${ }^{1}$, Masoud Bagherzadeh Kasiri ${ }^{2 *}$, Bahram Ajorloo ${ }^{3}$, Ghader \\ Ebrahimi $^{4}$ \\ ${ }^{1}$ M.Sc. in Archaeometry, Faculty of Applied Arts, Tabriz Islamic Art University, Tabriz, IRAN \\ ${ }^{2}$ Associate professor, Research Center on Restoration of Historical Monuments, Tabriz Islamic Art \\ University, Tabriz, IRAN \\ ${ }^{3}$ Associate professor, Faculty of Applied Arts, Tabriz Islamic Art University, Tabriz, IRAN \\ ${ }^{4}$ Ph.D. Candidate in Archaeology, University of Mohaghegh Ardabili, Ardabil, IRAN
}

Received: 10/08/2016

Accepted: $11 / 01 / 2017$

\begin{abstract}
Although the pottery is found in a massive amount in archaeological discoveries, these materials are the most important materials for different orientations in studies on the ancient people. One aspects of the study on ancient potteries, is the investigation about the painting and different colorants used for decorating potteries in variety patterns with different colors. This study aims to explore the ancient people knowledge and their experiments on creation of color by making up dying materials that could be found close to their dwells. The present work represented an attempt to discern experimentally the base and chemical composition of colorants used as decorative elements on ancient ceramics. Thus, five pieces of late Bronze painted pottery of the eastern Lake Urmia Basin (from the archaeological site of Kul Tepe of Ajabshir) were singled out. First, to determine whether the paint came from organic or inorganic sources and also to identify the existing anions and cations the Fourier-Transform Infrared Spectroscopy (FT-IR) technique was employed. The results demonstrated that the used coloring material has a mineral origin, where the sharp and strong peak at $465 \mathrm{~cm}-1$ of the spectrums confirmed that the nature of coloring agents consists of iron oxides. Next, for elemental analysis and studying the chemical structure and composition of the colorants Scanning Electron Microscope-Energy Dispersive X-Ray analysis (SEM-EDX) was used. SEM-EDX analysis result demonstrated the presence of iron and manganese $(\mathrm{Mn})$ content alongside other component elements of the ceramic bodies including $\mathrm{SiO}_{2}, \mathrm{MgO}, \mathrm{Al}_{2} \mathrm{O}_{3}$, and $\mathrm{K}_{2} \mathrm{O}$, where the results tallied with the FT-IR spectrums. On the basis of elemental analysis results, it could be said that iron oxides are the main components of coloring agents, where they could produce a variety of colors, ranging from red to dark brown. Moreover, the presence of manganese make the paintings darker, and consequently, the brighter nature of paintings of sample no. 3 of Kul Tepe and sample no. 1 of Haftvan could be the consequence of the miserable amount of this element (1.77 and $0.49 \%$, respectively). Finally, in order to confirm and complete the study, the specimens were subjected to X-Ray Diffraction analysis (XRD). This experiment also showed that the pigments used in ornamenting the sherds were mineral and comprised of Agite mineral $(\mathrm{Ca}(\mathrm{Fe}$, $\mathrm{Mg}) \mathrm{Si}_{2} \mathrm{O}_{6}$ ), as the coloring mineral, alongside other minerals including sodic and calcite feldspars. The
\end{abstract}

* Corresponding author: m.kasiri@tabriziau.ac.ir 
results obtained are in good agreements with the geology of the region, where the feldspars exist as the main minerals of both sites. Therefore experimental analysis on the pigments structure that used in the painting of Kul Tepe Urmia ware decorations in different ways and various laboratory equipments demonstrated that the pigments used in the pottery decorations have mineral source and presented various iron compounds in the paint of decorations. As result of this study, the presence of iron compounds in the soil of the Kul Tepe region, it could be said the ancient people did use the natural sources of colorants for decoration of their potteries. Moreover, the techniques and materials used for decoration of the potteries were the same at both side of the Lake Urmia.

Keywords: Iron oxide pigments, Painted pottery, Kul Tepe, Bronze Age, FT-IR, SEM-EDX, XRD. 
يخروهم باستانستهى

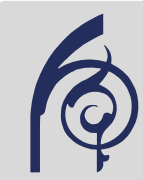

;

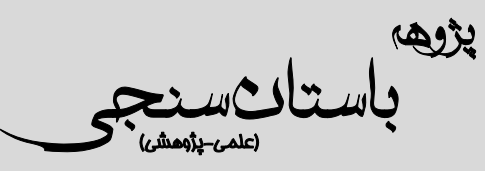

URL: http://jra-tabriziau.ir/

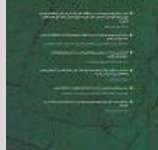

(c)

\section{(1)}

شناسايى ساختار رنَى سفالينههاى دوره مفرغ متأخر شرق درياجه اروميه؛ بر مبناى نمونههاى كؤل تبه عجب شير

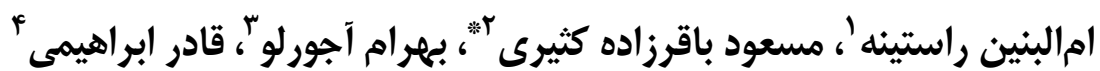

ا. كارشناس ارشد باستانسنجى، دانشگاه هنر اسلامى تبريز، تبريز، ايران

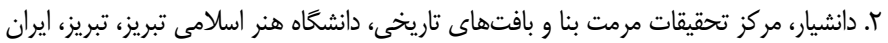

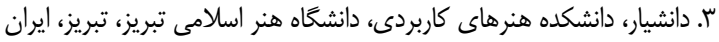

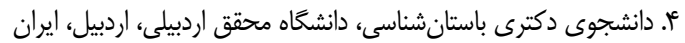

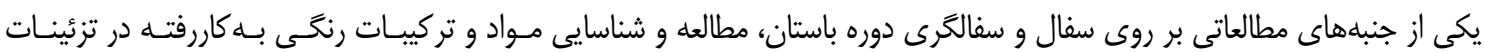

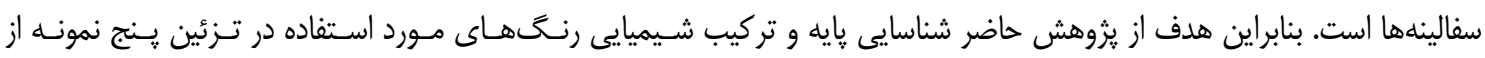

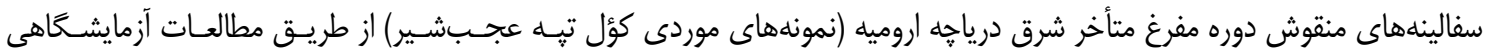

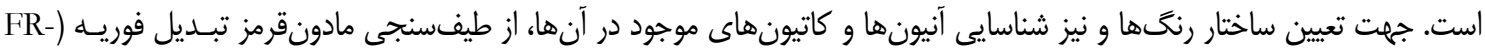

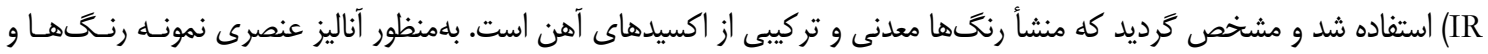

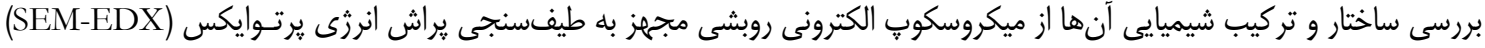

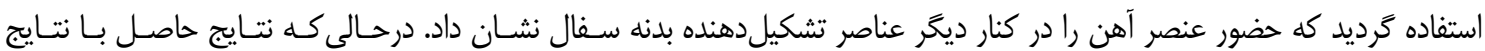

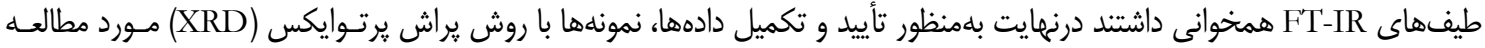

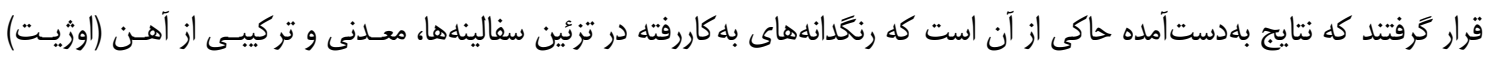

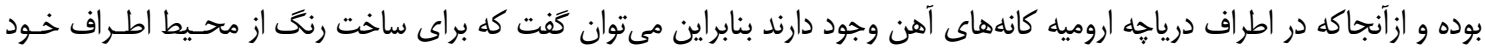
استفاده مىنمودهاند.

وازَّان كليدى: رنكدانههاى آهندار، سفال منقوش، كؤل تبه، دوره مفرغ، FRD SEM-EDX ،FT-IR.

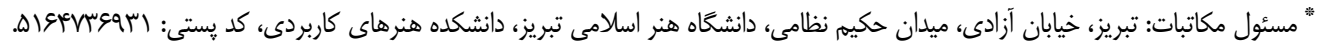

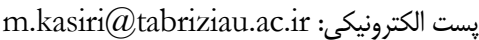
حق نشر متعلق به نويسنده(كان) است و نويسنده تحت مجوز Creative Commons Attribution License به مجله اجازه مىدهد مقاله خاب شـإهـ را با ديخران به اشتراك بحذارد منوط بر اينكه حقوق مؤلف اثر حفظ و به به انتشار اوليه مقاله در اين مجله اشاره شود. 


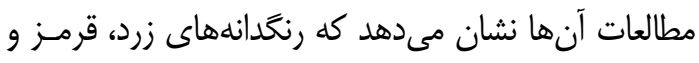

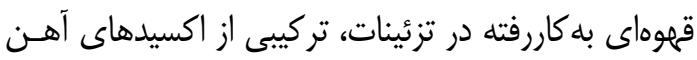

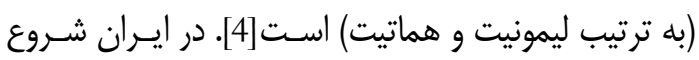

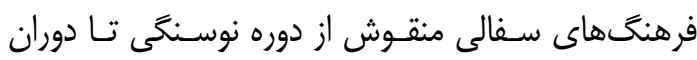
تاريخى را شامل مى شود[5]، بالينحال بيشـتر بـهـ مطالهـهـ

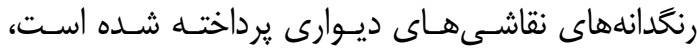

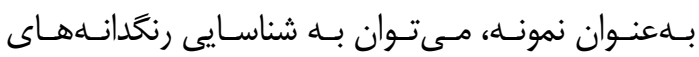

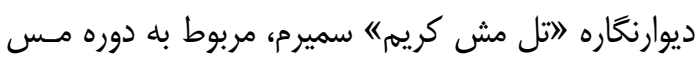

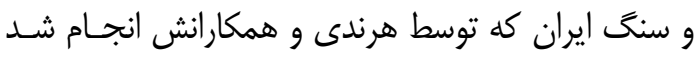

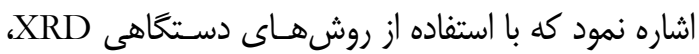

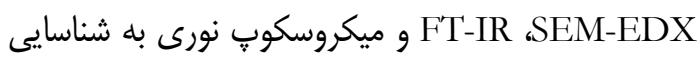

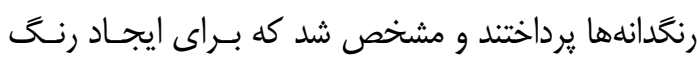

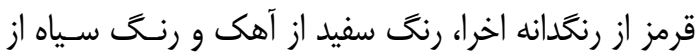
دوده زغالسنگ استفاده شده است[6].

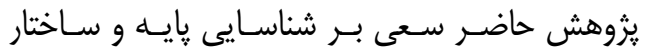

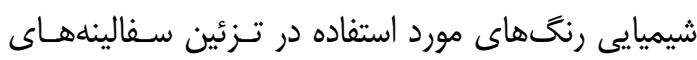

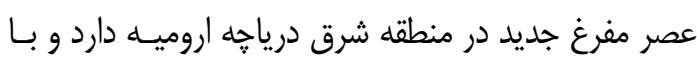

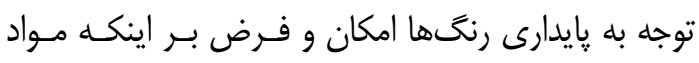
رنكى و تركيبات رنخـزاي به كاررفته در سفالينههـاى ايـن

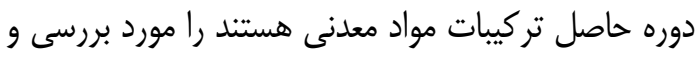

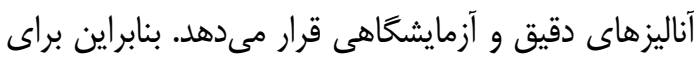

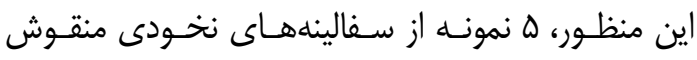

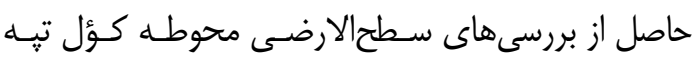

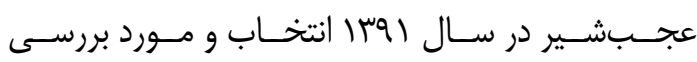

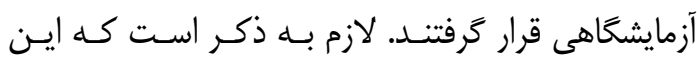

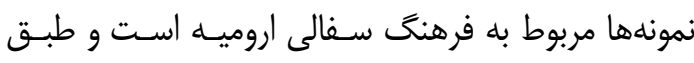

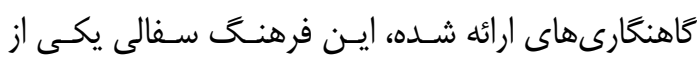

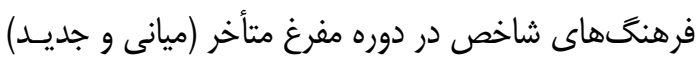

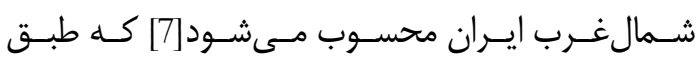

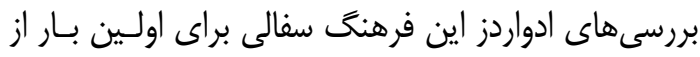

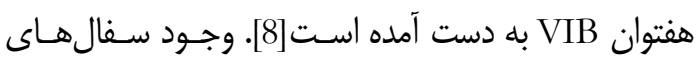

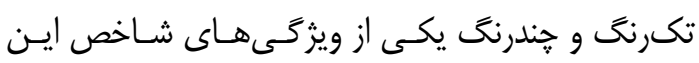

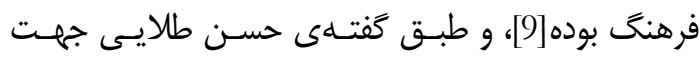

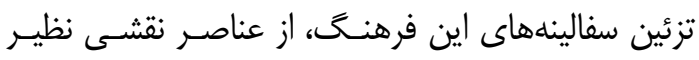

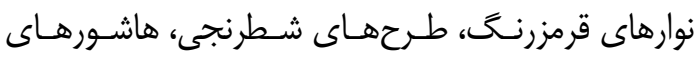

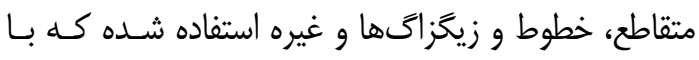

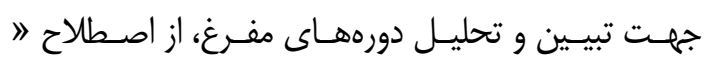
فرهنَ كورا- ارس " براى دوره مفرغ قديم كه از اواخـر

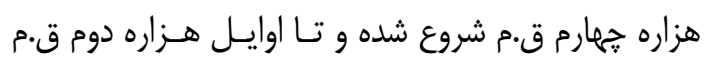

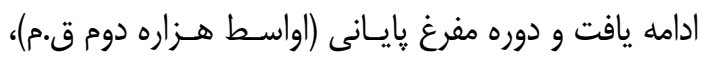

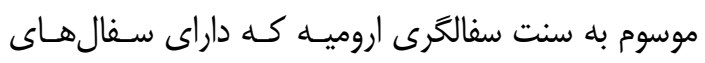

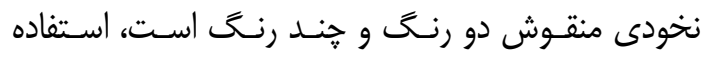

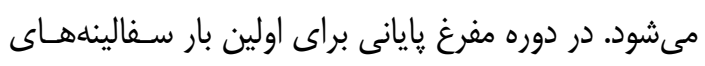

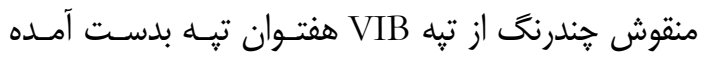

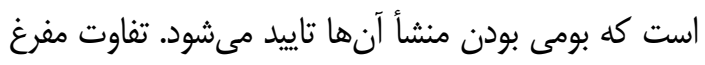

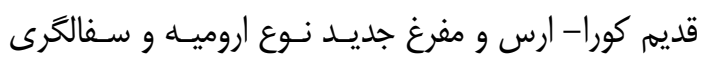

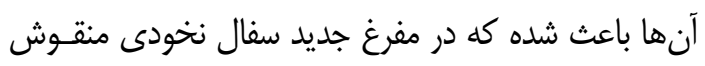

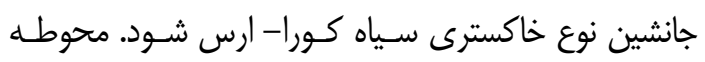

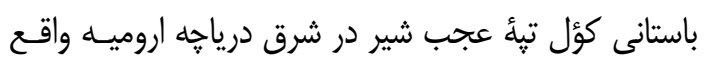

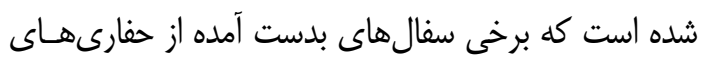

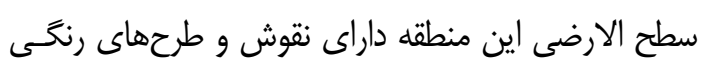

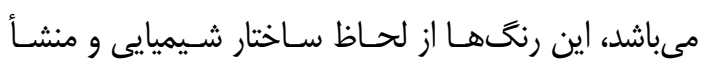
توليد تاكنون مورد مطالعه قرار نخرفتنهاند.

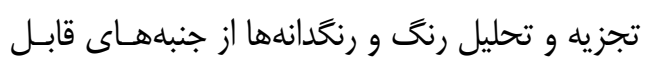
توجه در مطالعات باستانشناسـى و تـاريخ هنــر بــهـ شـمار

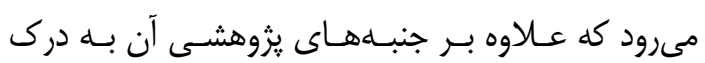

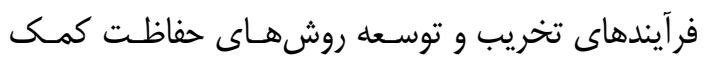

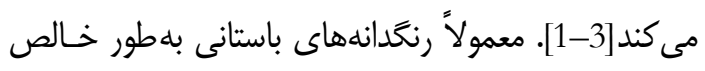

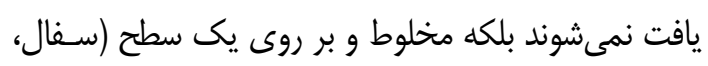

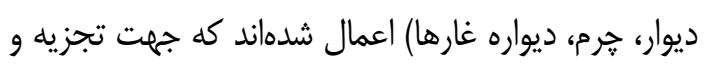

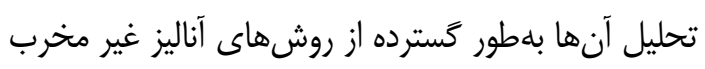

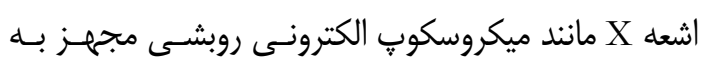

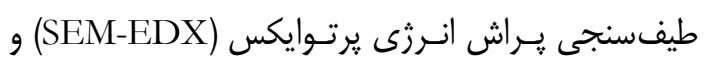

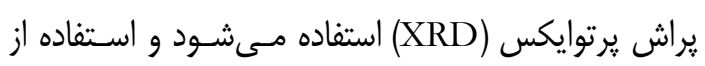

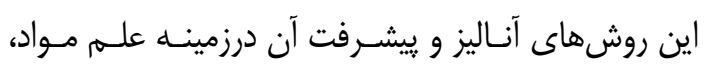

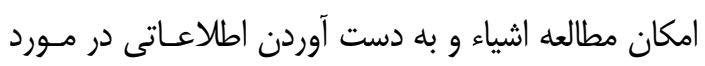

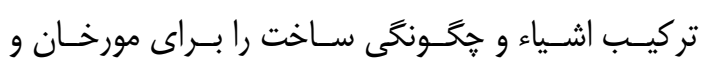

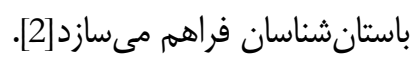

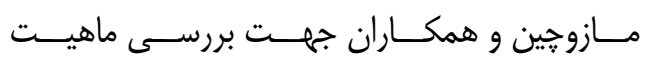

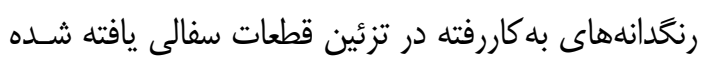
از حفارىهاى باستانشناسى يك ويلاى رومى در ويجنـزان

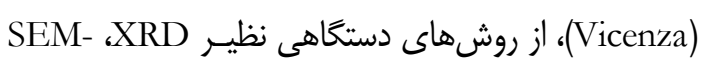

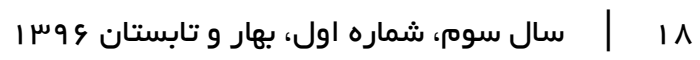


آذربايجان شرقى واقع شده است و براى اولين بار در سال

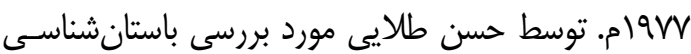

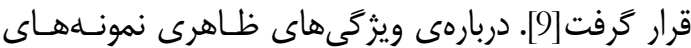

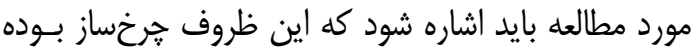

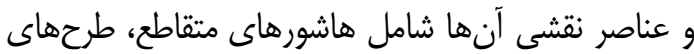

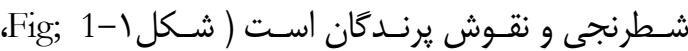

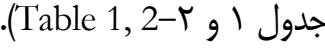

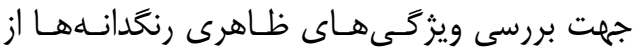

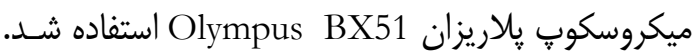

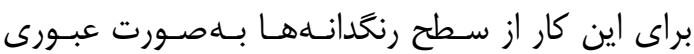

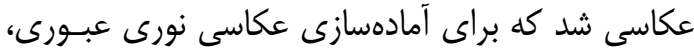

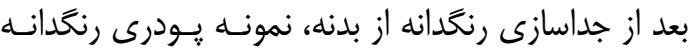

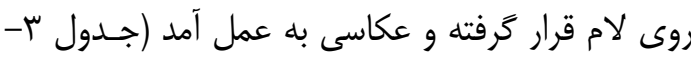

.Table 3

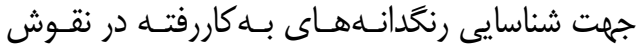

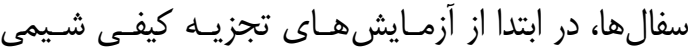

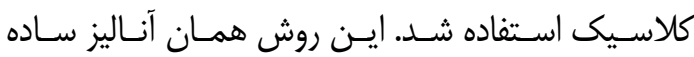

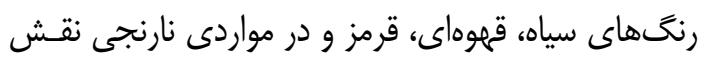

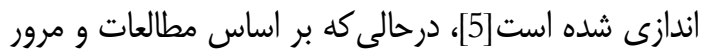

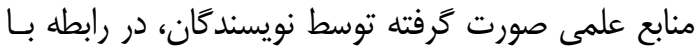

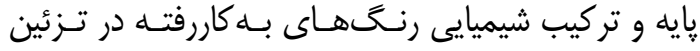

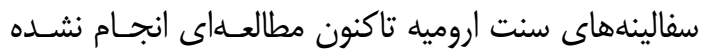

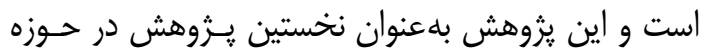

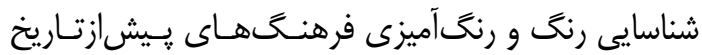
شمال غرب فلات ايران (آذربايجان) است.

\section{T. مواد و روشهاى مورد مطالعه}

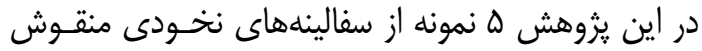

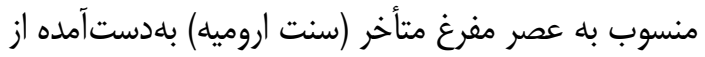

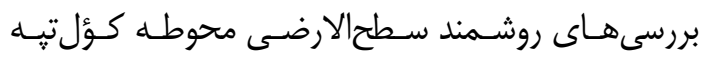

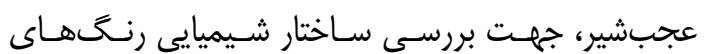

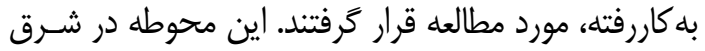

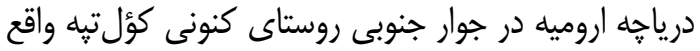
در "广 كيلومترى جنوب شرق شهرستان عجبشـير استان

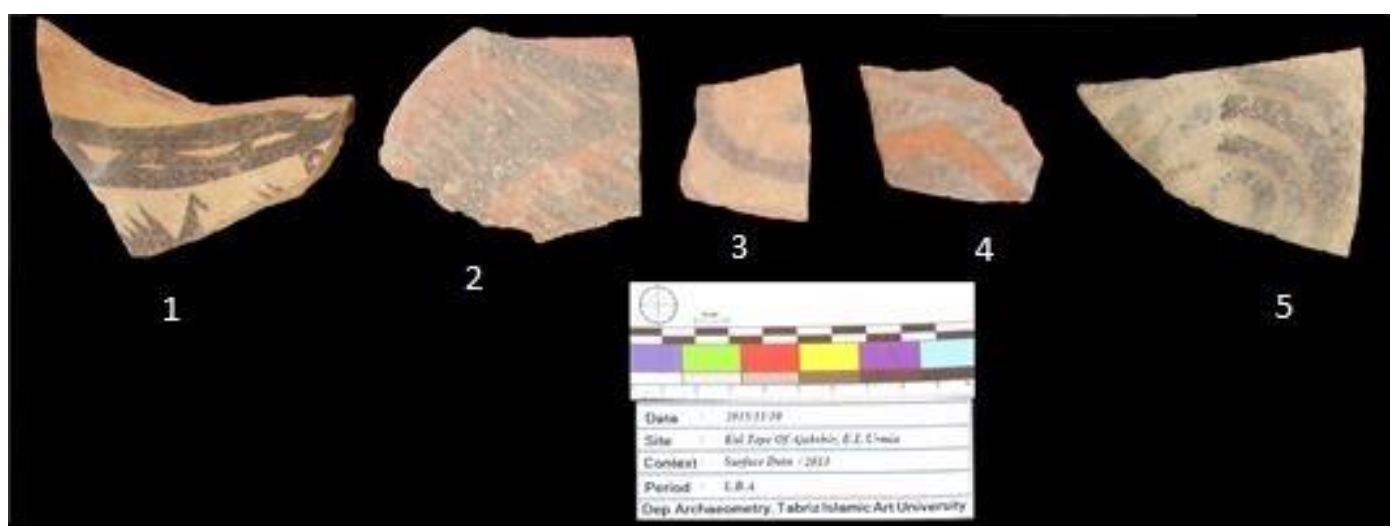

شكل ا: نمونه سفالهاى منقوش مورد مطالعه از محوطه كول تيه عجبشير

Fig; 1: Characteristics of the painted pottery samples from Kul Tepe Ajabshir جدول (: رسم فنى نمونه سفال هاى منقوش مورد مطالعه از محوطه كول تيه عجبشير Table 1: Illustrated samplesof the painted pottery from Kul Tepe Ajabshir

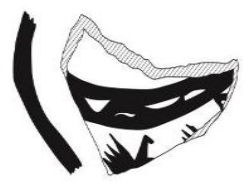

Sample 1

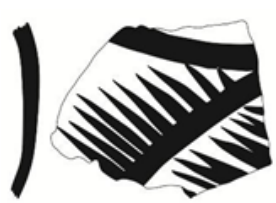

$-{ }^{-}$

Sample 2
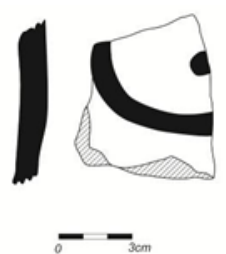

Sample 3
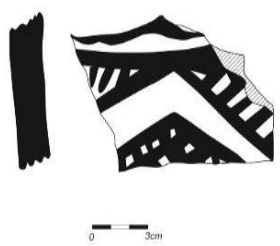

Sample 4

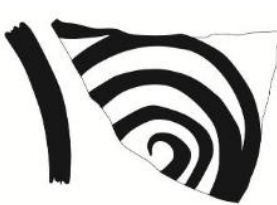

-

Sample 5 
جدول r: مشخصات ظاهرى نمونه سفال هاى منقوش مورد مطالعه محوطه كول تيه عجبشير

Table 2: Specification appearance painted pottery from Kul Tepe of Ajabshir

\begin{tabular}{|c|c|c|c|c|c|c|c|c|c|}
\hline \multirow{2}{*}{$\begin{array}{c}\text { شمارنهاه } \\
\text { Sample no. } \\
\text { Sample }\end{array}$} & \multirow{2}{*}{$\begin{array}{c}\text { كد رنخ بدنه } \\
\text { Munsell code }\end{array}$} & \multicolumn{2}{|c|}{, Color } & \multirow{2}{*}{$\begin{array}{c}\text { يوشش } \\
\text { Coating }\end{array}$} & \multirow{2}{*}{$\begin{array}{c}\text { تزئينات } \\
\text { Decoration }\end{array}$} & \multirow{2}{*}{$\begin{array}{c}\text { نوع قطعه } \\
\text { Sherd type }\end{array}$} & \multirow{2}{*}{ context } & \multirow{2}{*}{$\begin{array}{l}\text { محوطه } \\
\text { Site }\end{array}$} & \multirow{2}{*}{$\begin{array}{c}\text { ضخامت } \\
\text { Th. (mm) }\end{array}$} \\
\hline & & $\begin{array}{c}\text { بيرون } \\
\text { exterior }\end{array}$ & $\begin{array}{c}\text { درون } \\
\text { interior }\end{array}$ & & & & & & \\
\hline 1 & $5 \mathrm{YR} 7 / 4$ & $\begin{array}{l}\text { نخودى } \\
\text { Buff }\end{array}$ & $\begin{array}{l}\text { قرمز } \\
\text { Red }\end{array}$ & $\begin{array}{l}\text { دست مرطوب } \\
\text { Slip }\end{array}$ & $\begin{array}{c}\text { منقوش } \\
\text { painted }\end{array}$ & $\begin{array}{l}\text { گردن } \\
\text { neck }\end{array}$ & $\begin{array}{l}\text { سطحى } \\
\text { Surface }\end{array}$ & $\begin{array}{c}\text { كول تيه } \\
\text { Kul Tepe }\end{array}$ & 9 \\
\hline 3 & 5YR8/ 4 & $\begin{array}{l}\text { نخودى } \\
\text { Buff }\end{array}$ & $\begin{array}{l}\text { قرمز } \\
\text { Red }\end{array}$ & $\begin{array}{l}\text { دست مرطوب } \\
\text { Slip }\end{array}$ & $\begin{array}{c}\text { منقوش } \\
\text { painted }\end{array}$ & $\begin{array}{c}\text { بلدنd } \\
\text { shred }\end{array}$ & $\begin{array}{l}\text { سطحى } \\
\text { Surface }\end{array}$ & $\begin{array}{c}\text { كول تِّ } \\
\text { Kul Tepe }\end{array}$ & 7 \\
\hline 5 & 5YR8/ 4 & $\begin{array}{l}\text { نخودى } \\
\text { Buff }\end{array}$ & $\begin{array}{l}\text { قرمز } \\
\text { Red }\end{array}$ & $\begin{array}{c}\text { دست مرطوب } \\
\text { Slip }\end{array}$ & $\begin{array}{c}\text { منقوش } \\
\text { painted }\end{array}$ & $\begin{array}{c}\text { بدنd } \\
\text { shred }\end{array}$ & $\begin{array}{l}\text { سطحى } \\
\text { Surface }\end{array}$ & $\begin{array}{c}\text { كول تضه } \\
\text { Kul Tepe }\end{array}$ & 9 \\
\hline
\end{tabular}

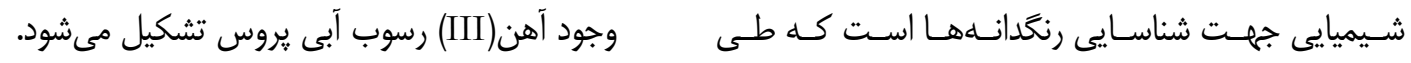
$4 \mathrm{Fe}^{3+}+3 \mathrm{~K}_{4}\left[\mathrm{Fe}(\mathrm{CN})_{6}\right] \rightarrow \mathrm{Fe}_{4}\left[\mathrm{Fe}(\mathrm{CN})_{6}\right]_{3} \downarrow+$ $12 \mathrm{~K}^{+}$

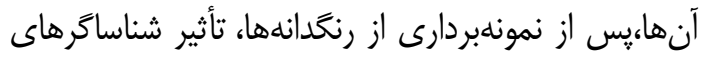

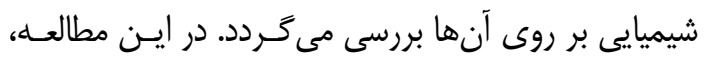

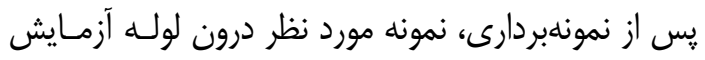

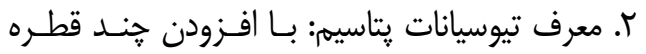

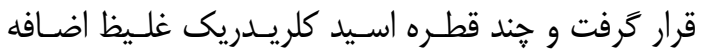
معرف / / مولار تيوسيانات يتاسيم به نمونسه، در صـورت

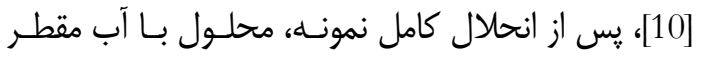
وجود آهن(III) رسوب قرمز خونى تشكيل مىشود[10].

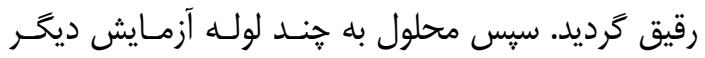
$\mathrm{Fe}^{3+}+6 \mathrm{KSCN} \rightarrow \mathrm{Fe}(\mathrm{SCN}) 6^{3-} \downarrow+6 \mathrm{~K}^{+}$ جهت افزودن هريك از معرفها، تقسيم شد. از آنجـا كـهـ

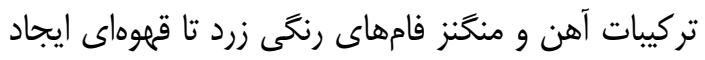

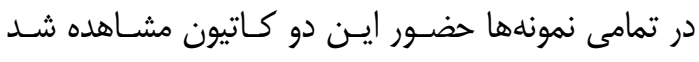

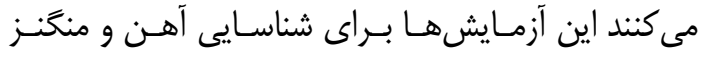
(جدان (Table 4)، بنابراين مىتوان كفت كه رنخدانهها موجود در نمونهها، به قرار زير انجام شدند.

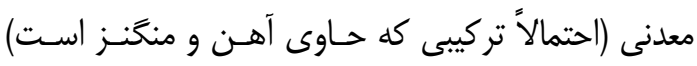

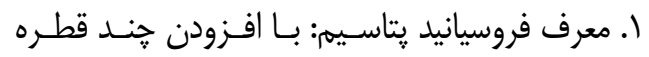

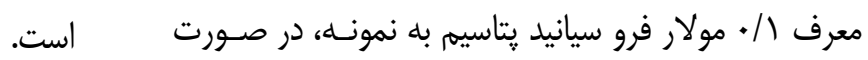

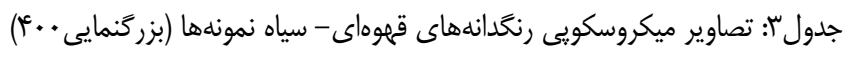
Table 3: Microscopic images selected from the painted pottery of black- Brown (Zoom in 400)

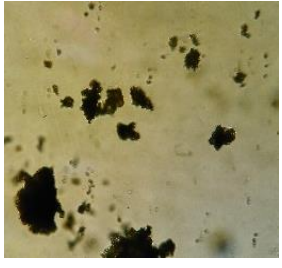

Sample 1

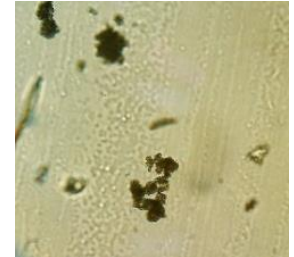

Sample 2

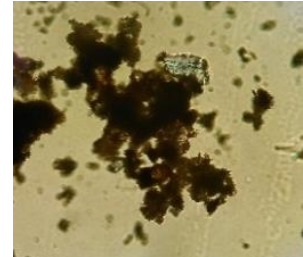

Sample 3

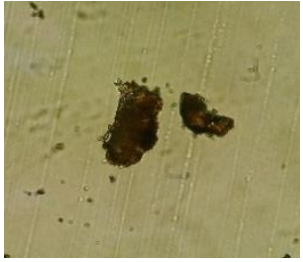

Sample 4

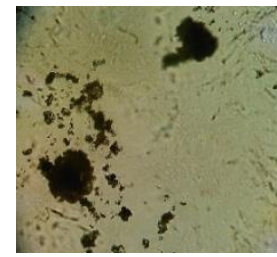

Sample 5 
جدول ثا: نتايج شناسايى كيفى نمونها به روش شيمى كلاسيك

Table 4: Results of spot tests on the samples

\begin{tabular}{|c|c|c|c|c|}
\hline \multicolumn{2}{|c|}{$\begin{array}{c}\text { منگingese } \\
\text { Manganes }\end{array}$} & \multicolumn{2}{|c|}{ آهن } & $\begin{array}{l}\text { كاتيون } \\
\text { Cation } \\
\end{array}$ \\
\hline هيدروكسيد سديم & $\begin{array}{c}\text { آمونياك } \\
\mathrm{NH}_{3} \\
\end{array}$ & $\begin{array}{c}\text { تيوسيانات يتاسيم } \\
\text { KSCN }\end{array}$ & $\begin{array}{c}\text { فروسيانيد يتاسيهم } \\
\mathrm{K}_{4}\left[\mathrm{Fe}(\mathrm{CN})_{6}\right]\end{array}$ & $\begin{array}{l}\text { شناساگر } \\
\text { Indicator }\end{array}$ \\
\hline+ & - & - & + & $\begin{array}{c}\text { نمونه } 1 \\
\text { Sample } 1\end{array}$ \\
\hline- & + & + & + & $\begin{array}{c}\text { Yمونه } \\
\text { Sample } 2\end{array}$ \\
\hline- & + & + & - & $\begin{array}{c}\text { نمونه } 3 \text { Sample } 3 \\
\text { Sam }\end{array}$ \\
\hline+ & + & - & + & $\begin{array}{c}\text { نمونه } 4 \\
\text { Sample } 4\end{array}$ \\
\hline+ & + & + & - & $\begin{array}{c}\text { نمونه } 5 \\
\text { Sample } 5\end{array}$ \\
\hline
\end{tabular}

كه يركاربردترين روش اجرايى اين آزمايش شيوه يودرى و

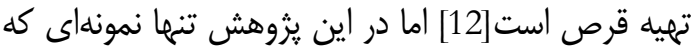

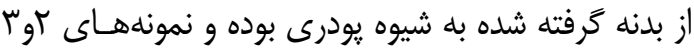
به دليل عدم وجود رنح كافى جهت تهيه قرص، قطعهاى

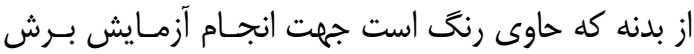
داده شد. مشخصات كامل دستخاههـاى مـورد اسـتفاده در

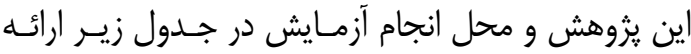
شده است (جدول ه-5 Table )

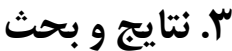
FT-IR أ آ آناليز نمونهها به روش تعيين ساختار رنخ نمونههاى مورد مطالعه و نيز شناسايى كروههاى آنيونى موجود در نمونههاى رنغَ توسط دستخاه

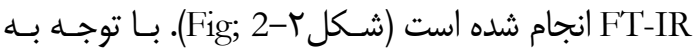

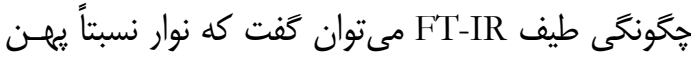
و متوسط محدودة

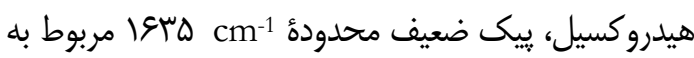

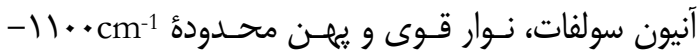

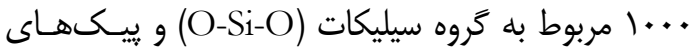

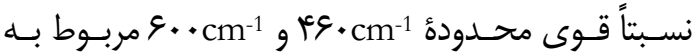

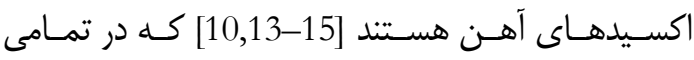
نمونهها تقريباً در همين محدودهها ظاهر شدهاند. تنهـا در نمونهى رنخ سفال شـماره ه كـه طيـف آن در شـكل س

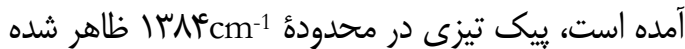

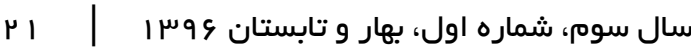

در ادامه، براى تكميل و صحت اين نتايج، نمونهها بـاــا طيفسنج FT-IR مورد بررسى قرار گرفتند. تعيين ساختار و نيز شناسايى گروههاى آنيونى موجود در نمونههاى رنى

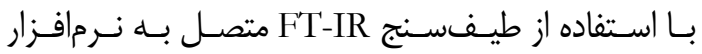
Spectra manager صـورت گرفـت. طيـفسـنجى در

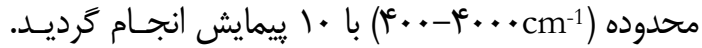

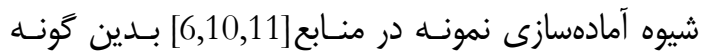

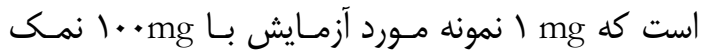

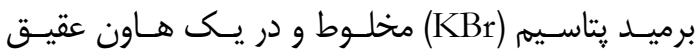

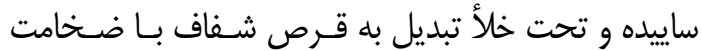
حدود mm أمىشود كه در اين تحقيـق نيـز بـر همـين

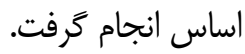
جهت شناسـايى عناصـر رنغخدانسهــا نيـز از دسـتخاه SEM-EDX استفاده شد كه طى آن از سطح نمونهها بـا ولتاز هKV به مدت •ع ثانيه آناليز اسكن صورت كرفت.

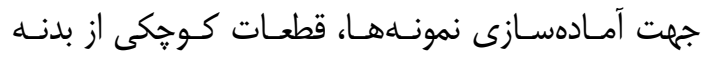

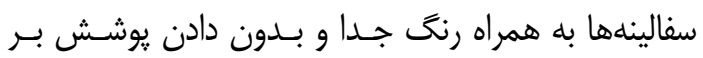

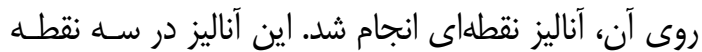

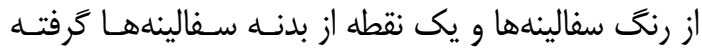
شد. درنهايت بهمنظور تكميل دادهها و بررسى سـاختارى رنخدانهها، يراش يرتوايكس (XRD) از سطح نمونسهــائ

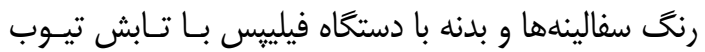

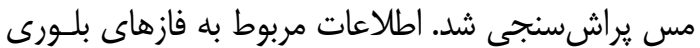

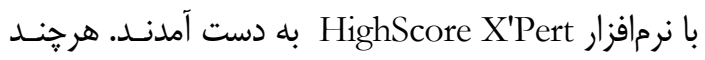


جدول ه: مشخصات دستخاههاى مورد استفاده در اين يثوهش

Table 5: Different analytical instruments used at this research

\begin{tabular}{|c|c|c|c|}
\hline $\begin{array}{c}\text { محل انجام آناليز } \\
\text { Analysis in Laboratory }\end{array}$ & $\begin{array}{c}\text { كشور سازنده } \\
\text { Made in } \\
\end{array}$ & مدل دستخاه & $\begin{array}{c}\text { نوع آزمون } \\
\text { Analysis sort }\end{array}$ \\
\hline $\begin{array}{c}\text { آزمايشگاه شيمى دانشخاه هنر اسلامى تبريز } \\
\text { Tabriz Islamic Art University; Chemistry } \\
\text { Laboratory. }\end{array}$ & Olympus, JAPAN & BX51 & $\begin{array}{l}\text { Polarized } \\
\text { Microscopy }\end{array}$ \\
\hline $\begin{array}{c}\text { آزمايشگاه شيمى دانشگاه هنر اسلامى تبريز } \\
\text { Tabriz Islamic Art University; Chemistry } \\
\text { Laboratory. }\end{array}$ & Jasco, JAPAN & FT/IR-680 plus & $\begin{array}{c}\text { FT-IR } \\
\text { Spectroscopy }\end{array}$ \\
\hline $\begin{array}{c}\text { آزمايشگاه مركزى دانشگاه تبريز } \\
\text { Tabriz University; Central Laboratory }\end{array}$ & TSCAN, CZECH Rep. & MIRA3 & \multirow{2}{*}{ SEM-EDX } \\
\hline $\begin{array}{c}\text { دانشگاه صنعتى سهند } \\
\text { Sahand University of Technology }\end{array}$ & ENGLAND & MV2300 & \\
\hline $\begin{array}{c}\text { شركت كانساران بينالود تهران } \\
\text { Tehran; Kansaran Binalud Co. }\end{array}$ & Philips, NETHERLANDS & PW1800 & $\mathrm{XRD}$ \\
\hline
\end{tabular}

بنابراين در اين يزوهش اين جذب به آنيون سـولفات [14] كه احتمالاً مربوط به گروههاى نيترو است كه در محدوده نسبت داده شد.

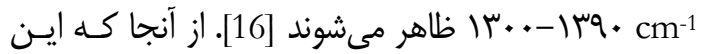
مشاهدات و مطالعات صورت كرفتــه از طريـق آنـاليز

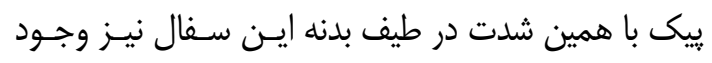

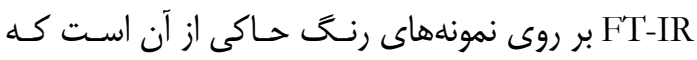

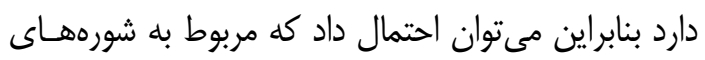

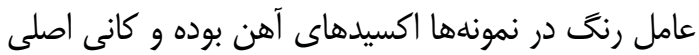

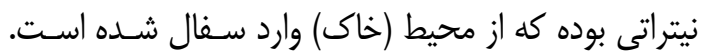

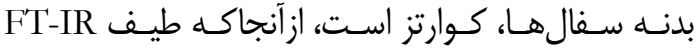

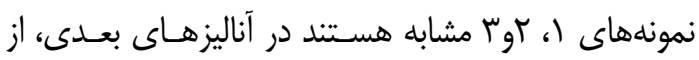

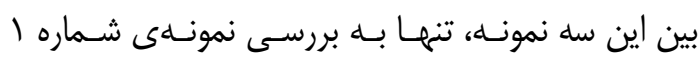
لازم به ذكر است كه محدوده

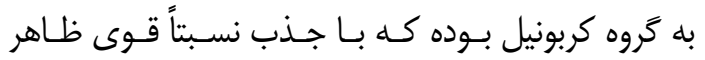

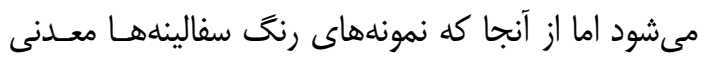

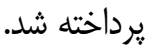

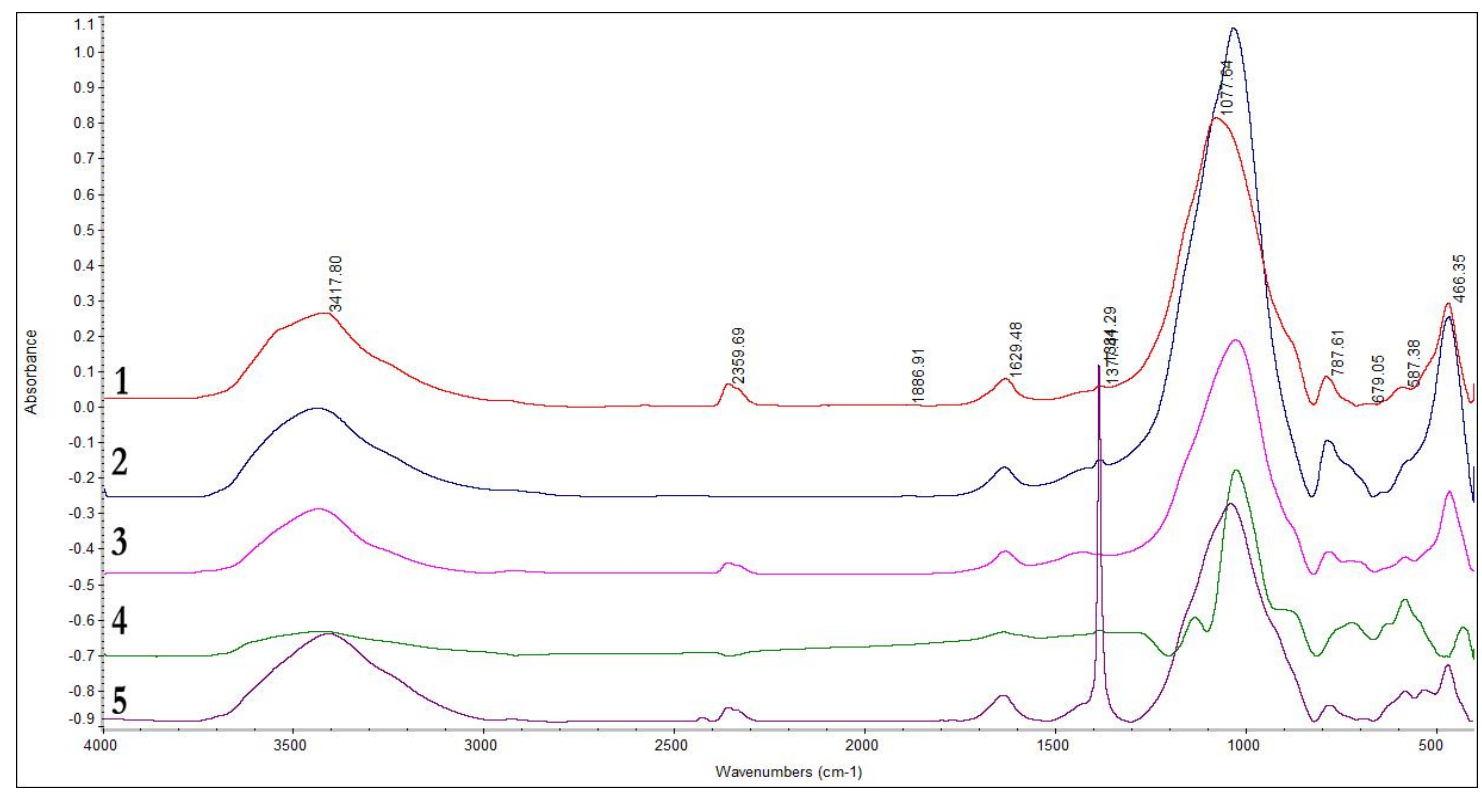

شكل ז: طيف FT-IR نمونههاى رنگ سفالينهها

Fig; 2: FT-IR spectrum of the potteries colorants 
بدنه و كانى آلبيت (فلدسوبات سوديك) باشـد كـه يكـى از كانىهاى موجود در ساختار سفال است [17,18]. ازآنجاكه

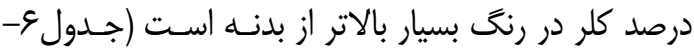
6

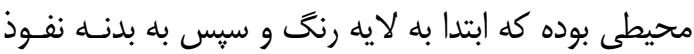

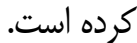

طبق نتايج آزمايشهـاى SEM-EDX نمونـهـــاى رنح و مقايسه آن با درصد تركيبات بدنه كه در جـدول

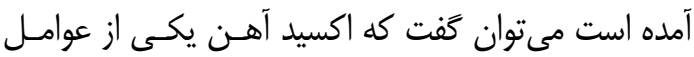
مؤثر در ايجاد رنكدانه قرمز سفالينهها بـوده كـه در آنـاليز

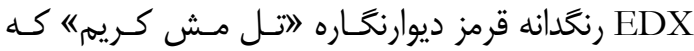

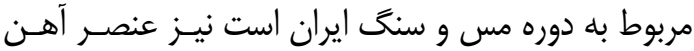

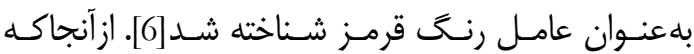
اكسيدهاى آهن تناليته رنكى بين قرمز تا قهـوماى ايجـاد

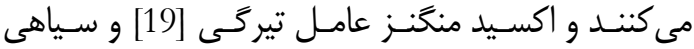
رنخـها در نظر كرفته مىشود، بنابراين مسىــوان احتمـال

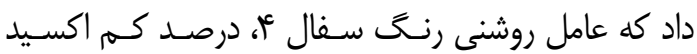
منكَنز موجود در ساختار رنخَ آن است. همجنين با توجـهـ

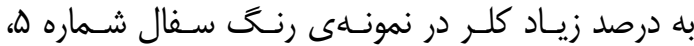

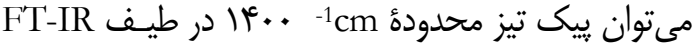
اين نمونه را به اكسيد كلر نسبت داد (جدول Table 7-V).

\section{س-ب. آناليز نمونهها به روش XRD}

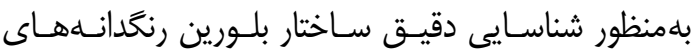
به كاررفته در تزئين سفالينهها، نمونههاى رنخ و بدنه به

\section{T-ז. آناليز نمونهها به روش SEM-EDX}

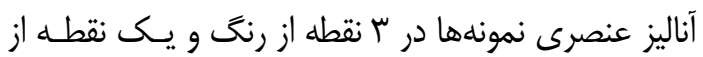

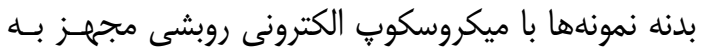
طيفسنج يراش يرتـوايكس (SEM-EDX) انجــام شـــ.

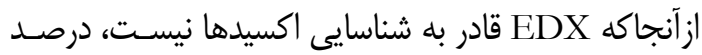

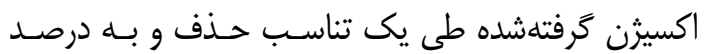
تمامى عناصر افزوده شده و بلهصـورت اكسـيد ارائهـ شـــه

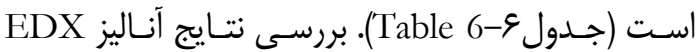
نمونه رنخ سفال ا نشان مى دهد كه با توجه بــه حضـور

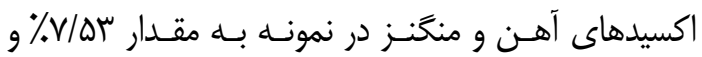

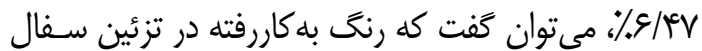
تركيبى از اكسيد آهن و منگنز است درحالى كه اكسيدهاى

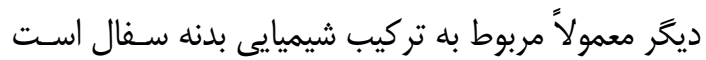

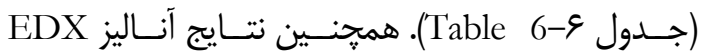

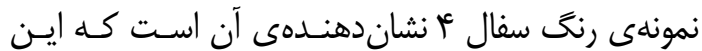

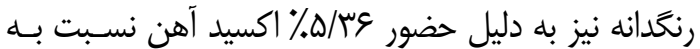

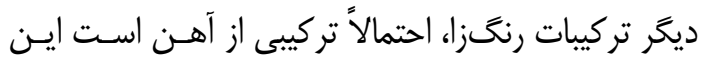

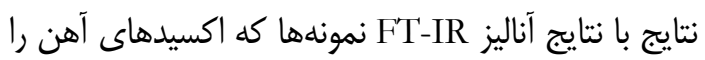
نشان مىدهند همخوانى دارد. بررسى نتايج آناليز EDX نمونه رنغ سفال ه نشان فارد

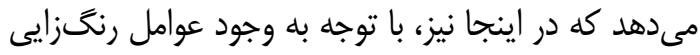

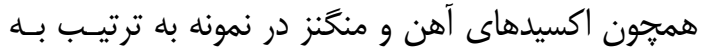

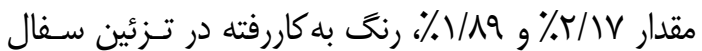
تركيبى از اكسيدهاى آهن و منگُنز است درحالى كه حضور

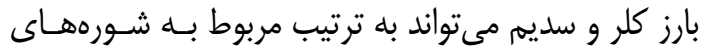

جدول ع: درصد وزنى تركيبات موجود در رنگ نمونهاى آناليز شده به روش EDX

Table 6: Results of colorants sample analyzed by EDX (w \%)

\begin{tabular}{|c|c|c|c|}
\hline Sample no. & 1 & 4 & 5 \\
\hline Oxide name & 1.62 & - & 23.11 \\
\hline $\mathrm{Na}_{2} \mathrm{O}$ & 2.94 & 1.83 & - \\
\hline $\mathrm{MgO}$ & 9.74 & 13.31 & 2.27 \\
\hline $\mathrm{Al}_{2} \mathrm{O}_{3}$ & 38.97 & 47.97 & 7.42 \\
\hline $\mathrm{SiO}_{2}$ & 7.66 & 4.83 & - \\
\hline $\mathrm{SO}_{2}$ & 5.68 & 11.31 & 18.24 \\
\hline $\mathrm{K}_{2} \mathrm{O}$ & 18.56 & 10.22 & -56 \\
\hline $\mathrm{CaO}$ & 0.83 & - & 1.89 \\
\hline $\mathrm{TiO} 2$ & 6.47 & 1.17 & 2.17 \\
\hline $\mathrm{MnO}$ & 7.53 & 5.36 & - \\
\hline $\mathrm{FeO}$ & - & 0.43 & - \\
\hline $\mathrm{ZnO}$ & - & 2.97 & 42.34 \\
\hline $\mathrm{BaO}$ & - & - & \\
\hline $\mathrm{Cl}$ & & & \\
\hline
\end{tabular}


جدول V: درصد وزنى تركيبات موجود در نمونهاى بدنه آناليز شده به روش EDX

Table 7: Results of body sample analyzed by EDX (\%w)

\begin{tabular}{|c|c|c|c|}
\hline Sample no. & 1 & 4 & 5 \\
\hline $\mathrm{Na}_{2} \mathrm{O}$ & & & \\
\hline $\mathrm{MgO}$ & 0.90 & 0.00 & 3.28 \\
\hline $\mathrm{Al}_{2} \mathrm{O}_{3}$ & 3.34 & 0.00 & 6.37 \\
\hline $\mathrm{SiO}_{2}$ & 16.39 & 14.79 & 11.75 \\
\hline $\mathrm{SO}_{2}$ & 57.47 & 42.98 & 29.48 \\
\hline $\mathrm{K}_{2} \mathrm{O}$ & 1.94 & 11.63 & 0.10 \\
\hline $\mathrm{CaO}$ & 5.04 & 2.47 & 3.35 \\
\hline $\mathrm{MnO}$ & 7.67 & 20.14 & 16.15 \\
\hline $\mathrm{FeO}$ & 2.05 & 4.74 & 0.98 \\
\hline $\mathrm{Cl}$ & 2.05 & 2.92 & 0.91 \\
\hline $\mathrm{NO}$ & 0.43 & 0.33 & 3.64 \\
\hline & 2.72 & 0.00 & 23.72 \\
\hline
\end{tabular}

ارتوكلاز، ألبيت و آنورتيت تركيبـات تشـكيلدهنــــه بدنــهـ

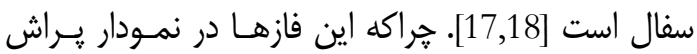

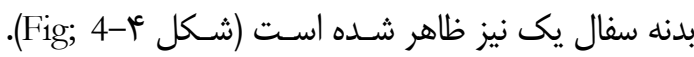
حضور فاز اوزيت (Ca(Fe,Mg)

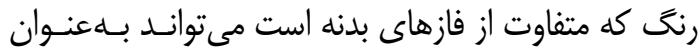
تركيب رنخ شناخته شود كه اين با نتايج حاصل از آناليز

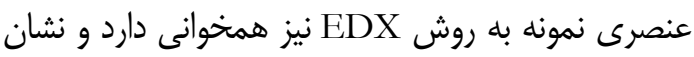

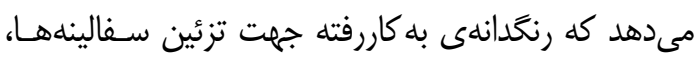

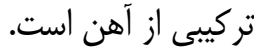

روش يراش يرتوايكس (XRD) نيـز مـورد بررسـى قـرار

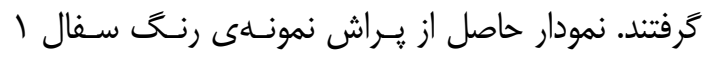

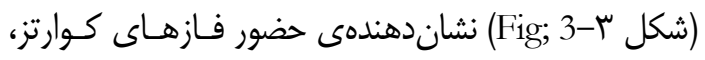

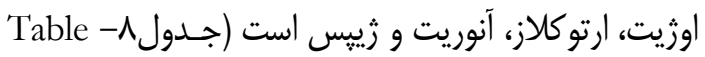
8). ازآنجاكه اشعه ايكس قدرت نفـوذ بـالايى داردو ولايـهـ

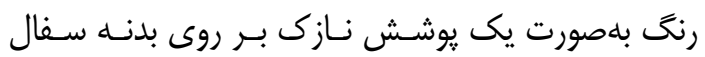

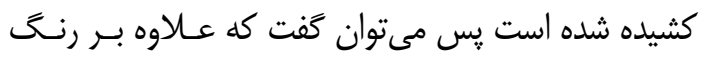

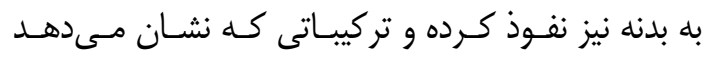

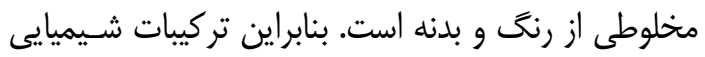

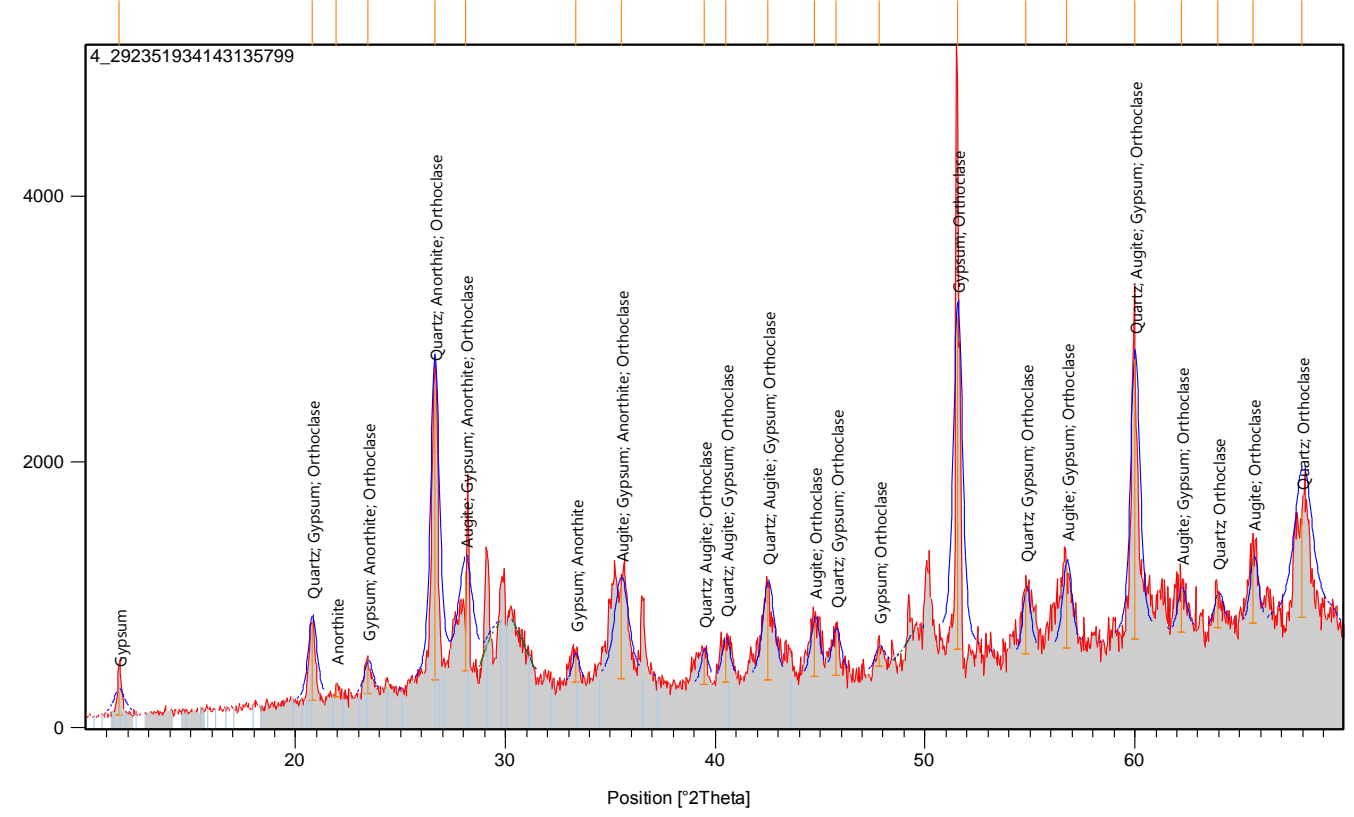

شكل "ا: دياگرام XRD نمونه رنگ سفال 1 نRD

Fig; 3: XRD diffractogram of pigment of sample no. 1 
Counts

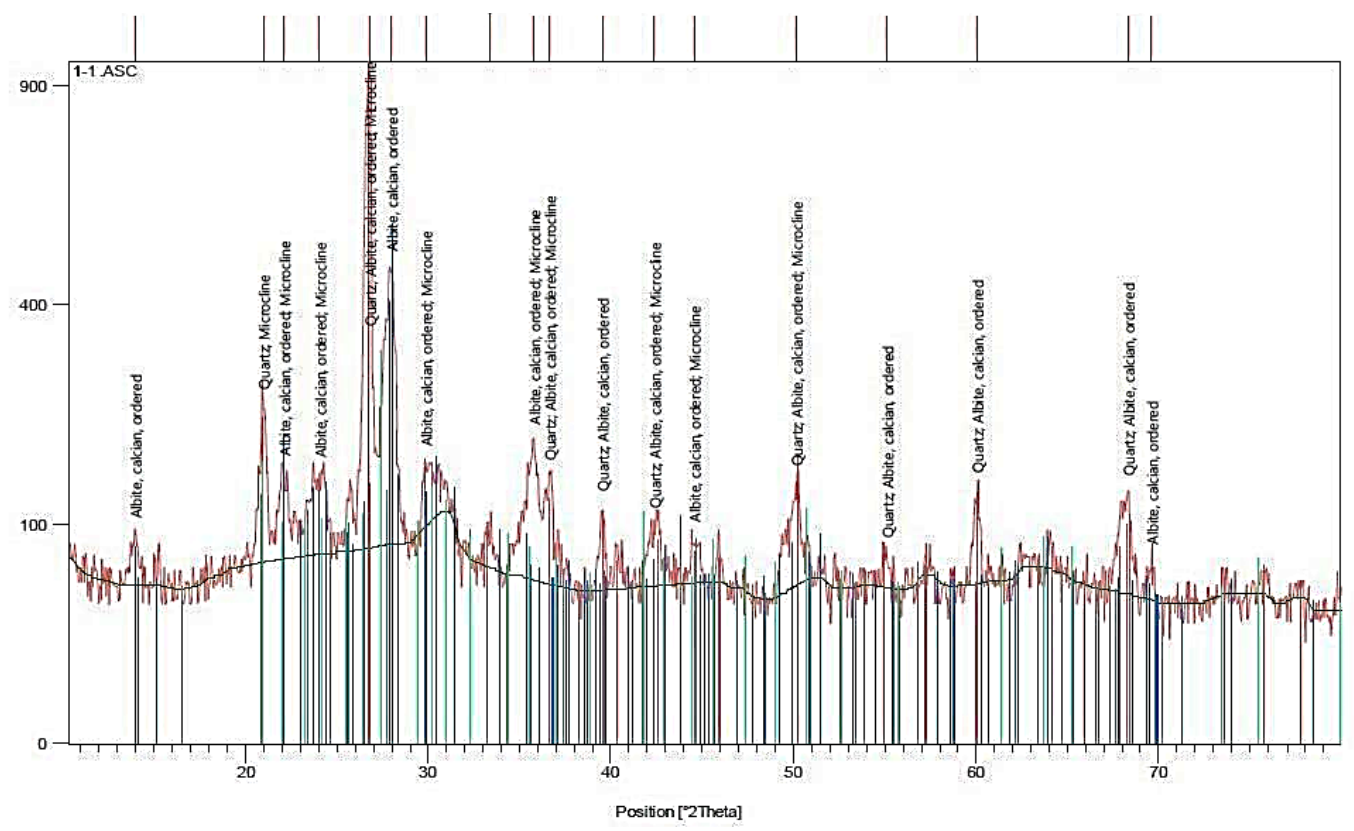

شكلث: دياترام XRD بدنه سفال I

Fig; 4: XRD diffractogram of body of sample no. 1

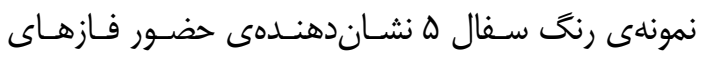

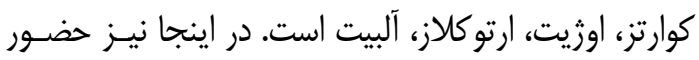

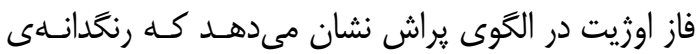
به كاررفنه جهت تزئين سفال همانند ديكر نمونهها تركيبى

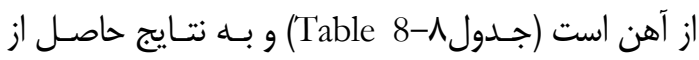

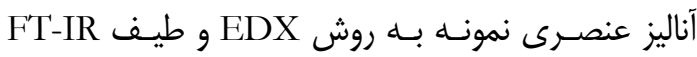

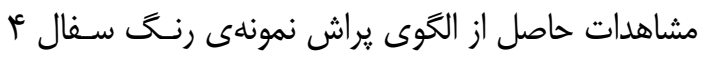

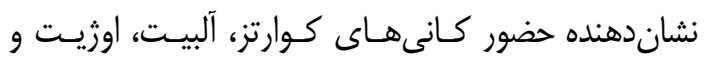
ارتوكلاز در نمونه است. فاز اوزيت در الكَوى يراش نشـان

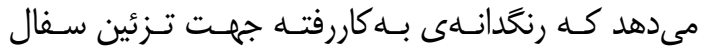
تركيبى از آهن است كه اين نتيجه با نتايج حاصل از آناليز

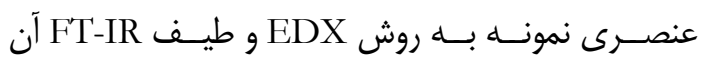

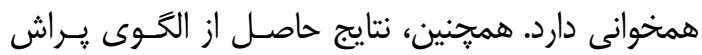

$$
\text { جدول م: نتايج آناليز XRD رنگ نمونهها }
$$

Table 8: Results of XRD analysis of the samples colorants

\begin{tabular}{|c|c|c|c|}
\hline نمونd & 1 & 4 & 5 \\
\hline $\begin{array}{c}\text { Quartz(33-1161) } \\
\mathrm{SiO}_{2} \\
\end{array}$ & + & + & + \\
\hline $\begin{array}{l}\text { Albite(09-0466) } \\
\mathrm{NaAlSi}_{3} \mathrm{O}_{8}\end{array}$ & - & + & + \\
\hline $\begin{array}{c}\text { Orthoclase(31-0966) } \\
\mathrm{KAlSi}_{3} \mathrm{O}_{8}\end{array}$ & + & + & + \\
\hline $\begin{array}{l}\text { Augite }(24-0203) \\
\mathrm{Ca}(\mathrm{Fe}, \mathrm{Mg}) \mathrm{Si}_{2} \mathrm{O}_{6}\end{array}$ & + & + & + \\
\hline $\begin{array}{l}\text { Analcime }(41-1478) \\
\mathrm{Na}\left(\mathrm{Si}_{2} \mathrm{Al}\right) \mathrm{O}_{6}, \mathrm{H}_{2} \mathrm{O}\end{array}$ & - & + & - \\
\hline $\begin{array}{c}\text { Anorthite }(18-1202) \\
(\mathrm{Ca}, \mathrm{Na})(\mathrm{Si}, \mathrm{Al})_{4} \mathrm{O}_{8}\end{array}$ & + & - & - \\
\hline $\begin{array}{c}\text { Gypsum }(33-0311) \\
\mathrm{CaSO}_{4}, 2 \mathrm{H}_{2} \mathrm{O}\end{array}$ & + & - & - \\
\hline
\end{tabular}




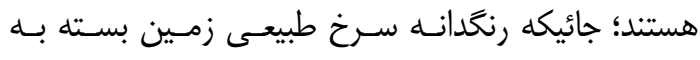

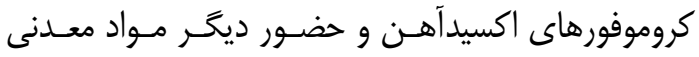

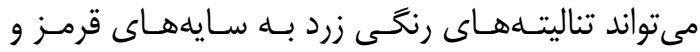

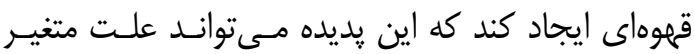

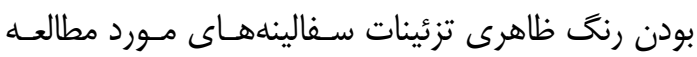
باشد. در مطالعات بعدى نيز مىتوان به تأثير حرارت كوره

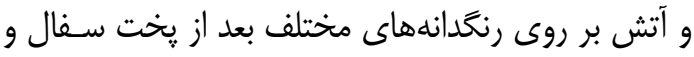
سـنجش درك سـفالخران دورههـاى مختلـف در ايجـاد رنخدانههاى متفاوت جهت تزئين سفالينهها، قبل و بعد از

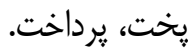

\section{سياسگَزارى}

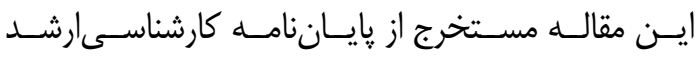

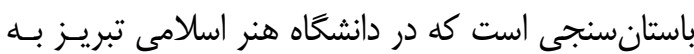

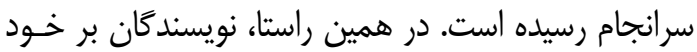

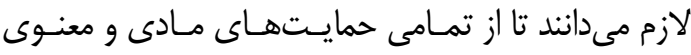
دانشگاه قدردانى نمايند.

\section{References}

[1] Franquelo ML, Duran A, Herrera LK, de Haro MCJ, Perez-Rodriguez JL. Comparison between micro-Raman and micro-FTIR spectroscopy techniques for the characterization of pigments from Southern Spain Cultural Heritage. J Molecular structure 2009;924:404-12.

[2] Galván-Ruiz M, Velázquez-Castillo R, PérezLara MA, Arjona JL, Baños L, RodríguezGarcía ME. Chemical and physical characterization of stuccos from a mexican colonial building: El museo del calendario of queretaro. Archaeometry 2009;51:701-14. doi:https://10.1111/j.1475-4754.2008.00456.x.

[3] Akyuz S, Akyuz T, Basaran S, Bolcal C, Gulec A. Analysis of ancient potteries using FT-IR, micro-Raman and EDXRF spectrometry. Vibrational spectroscopy 2008;48:276-80.

[4] Mazzocchin GA, Vianello A, Minghelli S, Rudello D. Analysis of roman wall paintings from the Thermae of "Iulia Concordia". Archaeometry 2010;52:644-55. doi:https:// 10.1111/j.1475-4754.2009.00501.x.

[5] Talai H. Iran iron age. Fourth. Tehran: SAMT; 2013. [in Persian]

[طلايى حسن. عصر آهن ايـران. جـاٍ جهـارم. تهــران:

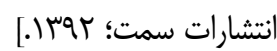

[6] Harandi D, Taheri MH, Sardari A.
بطور كلى، در مـورد مطالعـات XRD نمونـهـهـاى رنــ

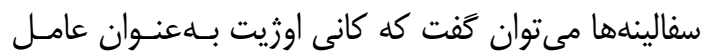
رنــَزا در سـفالينههــا حضـور داشـته و بقيـهـ تركيبـات

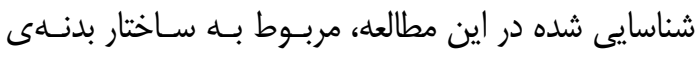
سفالينهها هستند. وجود فـاز اوزيـت در رنــ سـفالينههـا EDX مىتواند درصد نسبتاً بالاى منيزيم موجود در نتايج را نيز توجيه كند.

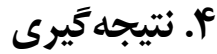

بررسى ساختار رنخَهاى به كاررفته در تزئين سفالينههاى

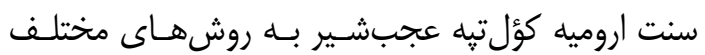
آزمايشگاهى، شامل آزمايش هاى شيمى تر، طيـفســنج

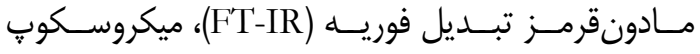

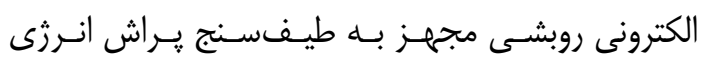
يرتوايكس (EDX) و يـراش يرتـوايكس (XRD) نشـان

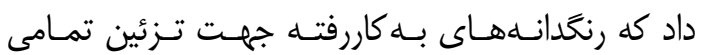
سفالينهها، معدنى و تركيبى از آهن (Ca(Fe,Mg)Si

Identification of pigments of Tal-e Mash Karim wall painting at the Chalcolithic site of Iran. Journal of Color Science and Technology 2015;9:187-97. [Original in Persian with English Abstract]

]هرندى دانيال، طاهرى محمدحسين، سردارى عليرضـا.

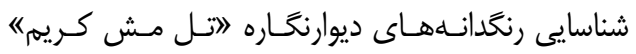

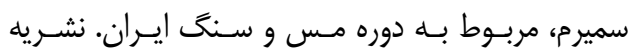

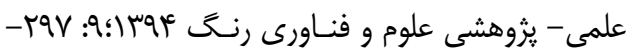

$\left[. \Gamma^{\circ} \cdot 9\right.$

[7] Hajizadeh K, Kazempour M, Abargouei H. Determine the culture of the second millennium BC, northwest Iran. Tehran: Samira; 2012. [in Persian]

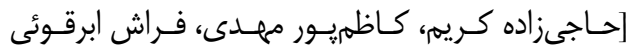

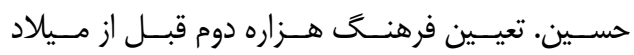

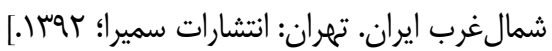

[8] Edwards MR. The pottery of Haftavan VIB (Urmia ware). Iran 1981;19:101-40.

[9] Talai H. Iran Bronze Age. Fifth. Tehran: SAMT; 2012. [in Persian]

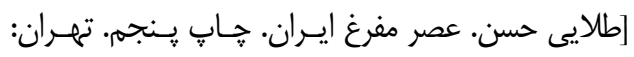

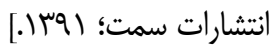

[10] Stuart BH. Analytical techniques in materials 
conservation. John Wiley \& Sons; 2007.

[11] Casadio F, Chiari G, Simon S. Evaluation of binder/aggregate ratios in archaeological lime mortars with carbonate aggregate: A comparative assessment of chemical, mechanical and microscopic approaches. Archaeometry 2005;47:671-89. doi:https:// 10.1111/j.1475-4754.2005.00226.x.

[12] Skoog D, Holler F, Nieman T. Principles of instrumental analysis. Philadelphia: Saunders College Pub; 1998.

[13] Edreira MC, Feliu MJ, Fernández-Lorenzo C, Martın J. Roman wall paintings characterization from Cripta del Museo and Alcazaba in Mérida (Spain): chromatic, energy dispersive X-ray flurescence spectroscopic, Xray diffraction and Fourier transform infrared spectroscopic analysis. Analytica Chimica Acta 2001;434:331-45.

[14] Mazzocchin GA, Agnoli F, Colpo I. Investigation of roman age pigments found on pottery fragments. Analytica Chimica Acta 2003;478:147-61.
[15] Darchuk L, Tsybrii Z, Worobiec A, Vázquez C, Palacios OM, Stefaniak EA, et al. Argentinean prehistoric pigments' study by combined SEM/EDX and molecular spectroscopy. Spectrochimica Acta Part A: Molecular and Biomolecular Spectroscopy 2010;75:1398-402.

[16] Pavia D, Lampman G, Kriz G. Introduction to spectros copy. Cengage Learning; 2008.

[17] Sharveh A, Anvshfr M. Glaze ceramic tiles. Third. Tehran: Gothenburg; 1999. [in Persian]

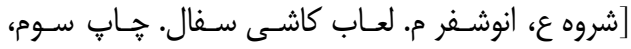
تهران: انتشارات كوتنبرگ؛

[18] Emami M, Trettin R. Mineralogical and chemical investigations on the ceramic technology in Čogà Zanbil,(Iran, 1250 BC). Periodico di Mineralogia Vol. 81, 3 dicembre 2012:359.

[19] Hradil D, Grygar T, Hradilová J, Bezdička P. Clay and iron oxide pigments in the history of painting. Applied Clay Science 2003;22:22336. 